\title{
Social Integration and the Mental Health of Black Adolescents
}

\author{
Theda Rose \\ University of Maryland \\ Joseph Shields \\ The Catholic University of America
}

\author{
Sean Joe \\ University of Michigan \\ Cleopatra H. Caldwell \\ University of Michigan
}

\begin{abstract}
The influence of family, school, and religious social contexts on the mental health of Black adolescents has been understudied. This study used Durkheim's social integration theory to examine these associations in a nationally representative sample of 1,170 Black adolescents, ages 13-17. Mental health was represented by positive and negative psychosocial well-being indicators. Results showed that adolescents' integration into family and school were related to better mental health. In addition, commitment to religious involvement positively influenced mental health. Although the direct effect of religious involvement was inversely related to mental health, mediation analyses revealed a positive influence through religious commitment. Findings suggest a greater emphasis on all three social contexts when designing strategies to improve the mental health of Black adolescents.
\end{abstract}

Adolescence is a critical developmental period characterized by biological, cognitive, and psychosocial changes (Crockett \& Petersen, 1993). Although most young people negotiate this life stage without serious difficulty (Loh \& Wragg, 2004), the literature acknowledges a persistence of adverse social and psychological development trajectories for today's generation of U.S. adolescents (Kessler et al., 2012). Among adolescents, Black adolescents could be considered an especially vulnerable subpopulation. Greater psychiatric problems (e.g., anxiety) and higher rates of comorbidity have been reported among this group compared to their White or Hispanic counterparts (Chen, Killeya-Jones, \& Vega, 2005). Kessler et al. (2012) reported a slightly higher prevalence rate of any disorder (e.g., mood, impulse disorders) for nonHispanic Black adolescents $(46 \%)$ in relation to non-Hispanic White adolescents (42\%). Given their lower representation in mental health research

The NSAL is supported by the National Institute of Mental Health (U01-MH57716) with supplemental support from the OBSSR Office of Behavioral and Social Science Research and the National Institute on Drug Abuse at the National Institutes of Health and the University of Michigan to Dr. James S. Jackson. Dr. Joe was supported by a grant (R01-MH82807) from the National Institute of Mental Health.

Correspondence concerning this article should be addressed to Theda Rose, School of Social Work, University of Maryland, 525 W. Redwood Street, Baltimore, MD 21201. Electronic mail may be sent to trose@ssw.umaryland.edu.
(U.S. Department of Health and Human Services, 2001), there is also less information about the mental health of this group.

Researchers have called for a reduced emphasis on mental illness and increased scientific attention to understanding positive mental health outcomes, particularly among adolescents (Loh \& Wragg, 2004). Mental health has been traditionally used as a proxy for the absence of mental illness (Smith, 1959). However, empirical research supports the argument that, conceptually, absence of illness alone does not imply well-being. For example, Harker (2001) found that depression and positive well-being are separate constructs, such that low levels of depression did not ensure higher levels of positive well-being. Similarly, Keyes (2006) reported that adolescents who were flourishing, defined as exhibiting positive emotions and functioning, had lower levels of depression and conduct issues as well as higher levels of psychosocial functioning (e.g., self-concept). Kazdin (1993) argued that mental health incorporates "the absence of dysfunction in psychological, emotional, behavioral, and social spheres ... optimal functioning or well-being in psychological and social domains" (p. 128). More

(C) 2013 The Authors

Child Development (C) 2013 Society for Research in Child Development, Inc. All rights reserved. 0009-3920/2014/8503-0013

DOI: $10.1111 /$ cdev.12182 
recently, the World Health Organization (WHO) defined mental health as:

a state of well-being in which the individual realizes his or her own abilities, can cope with the normal stresses of life, can work productively and fruitfully, and is able to make a contribution to his or her own community. (WHO, 2010, p. 1)

These conceptualizations of mental health underscore the inclusion of positive psychosocial wellbeing factors such as high self-concept, mastery, and successful coping and problem solving. Consequently, for this study, mental health will be conceptualized as both the presence of positive psychosocial well-being and the absence of or lower psychosocial dysfunction.

Personal, social, cultural, economic, and broader environmental factors have the potential to impact adolescent mental health (Rowling, 2006). Developmental adjustment and functioning in children and adolescents are shaped by constant interactions with others in family, peer, community, and larger cultural environments (Knopf, Park, \& Mulye, 2008). These social contexts within which an adolescent is embedded are their primary sources of social integration. This includes contexts such as family, school, and religion (Maimon \& Kuhl, 2008). Thus, social integration is defined, in this study, as the level of adolescent involvement with and attachment to their primary and extended family, schools, and religious institutions. Employing Durkheim's theoretical framework, the purpose of this study is to examine how these three key domains of social integration influence the mental health of Black adolescents using a nationally representative sample. Durkheim's theory is discussed, followed by a review of the literature on family, school, and religion in relation to adolescent psychosocial well-being.

\section{Durkheim's Social Integration Theory}

Durkheim's theory recognizes that individuals are social beings whose lives are immeasurably shaped by the nature of their social relationships. Although Durkheim's work focused on macrolevel influences on suicide, the theory postulates that weak attachments to societal institutions result in lower psychosocial well-being, and stronger attachments and shared values and goals among members of a social group, derived from the quantity and intensity of their interaction, foster well-being (Durkheim, 1951; Thorlindsson \& Bjarnason, 1998).
Social integration incorporates two main ideas. First, the theory postulates that a sense of control or adherence to societal norms is a guide for appropriate human interaction (Durkheim, 1951). This proposition suggests that the greater the attachment to the social group, the more the individual will conform to the norms within the group, not only as a guide for their behavior but also to sustain the affective ties of those important relationships (Stark \& Bainbridge, 1996). The theory secondarily suggests that cohesive group arrangements, developed through positive and consistent exchanges and interaction among members, encourage an atmosphere of support and constructive attachments among group members, consequently leading to better individual psychosocial well-being outcomes. Conversely, lack of these exchanges or weak levels of social integration among group members can be the basis for disconnection, leading to negative individual psychosocial well-being outcomes. Consistent with the theory's postulations, Durkheim suggested that better well-being, namely, lower inclination toward suicide, is due to membership in family groups, where there are strong attachments, consistency of interaction, and supportive relationships (Durkheim, 1951; Thorlindsson \& Bjarnason, 1998). Similarly, he maintained that religion creates social integration due to its ability to foster a more intensive collective life, resulting in better psychosocial well-being outcomes (Durkheim, 1951). Building on Durkheim's work, Hirschi (1969) identified four key integrative functions (attachment, commitment, involvement, and belief) that characterized the social bond. Applying this framework to schools, he argued that adolescents with higher levels of attachment or commitment to school and school activities should exhibit less of a propensity toward delinquent behavior (Hirschi, 1969). Using Durkheim's latter supposition, this study proposes that the closer, and more supported, involved, and committed adolescents are to their family, school, and religious developmental contexts, the greater the integration into those social contexts.

\section{Family}

The family is considered the chief socialization context during a child's formative years and is thought to have significant implications for the development of psychosocial well-being beyond the childhood years (Grusec, 2011). Within Black communities, family includes the extended family structure (biologically related and fictive kin) that 
persists as a viable network for the provision of tangible and intangible support, access to coping mechanisms, and the development and exchange of essential resources (Taylor, Chatters, \& Celious, 2003).

Besides familial structure, the affective domains of family (e.g., closeness, support) have been identified as important elements of integration (Maimon \& Kuhl, 2008). Family closeness, produced by positive family exchanges, plays a critical role in facilitating a sense of security, healthy decision making, better coping skills, and reduction in adolescent problem behavior (Ackard, Neumark-Sztainer, Story, \& Perry, 2006). Strong connections to parents provide emotional stability for the adolescent above and beyond other important relational contexts (e.g., school; Maimon \& Kuhl, 2008) and are consonant with the emphasis in Durkheim's theory that family support and closeness matter to the psychosocial well-being of an adolescent. Indeed, supportive family settings contributed to the development of a positive sense of self for African American adolescents (Bean, Bush, McKenry, \& Wilson, 2003) and fostered better global well-being and socioemotional adjustment (Demo \& Acock, 1996). Similarly, adolescents' perceptions of feeling close to parents predicted better self-esteem and greater life satisfaction (Wenk, Hardesty, Morgan, \& Blair, 1994). Furthermore, Margolin (2006) reported that Black sixth-grade adolescents who perceived themselves as having at least one family member who was caring and supportive experienced less depression, social anxiety, and loneliness. Other contexts such as peer and school were unrelated to decreased internalizing problems in the same study.

Consistent interaction between family members is also a vital aspect of family integration. Supportive child-caregiver communication developed through positive reinforcement, emotional availability, and encouragement is purported to produce a strong sense of self, mastery, and competence as children and adolescents successfully navigate critical developmental stages (Erickson, 1968). For example, better parental communication and valuing parent opinion on important issues over friends' opinions was related to fewer self-esteem problems and lower depression among middle and high school adolescents (Ackard et al., 2006). Thus, family closeness, support, and communication are key family integrative processes and are salient to better psychosocial well-being and fewer adverse mental health outcomes among adolescents. This study seeks to confirm the role of familial influence on adolescent mental health while considering other important developmental contexts.

\section{School}

Schools have been cited as the second strongest socializing influence after family (Simons-Morton, Crump, Haynie, \& Saylor, 1999), suggesting its critical role in the process of adolescent development. Indeed, most adolescents spend a significant portion of their day in school settings that afford them the opportunity to develop relationships with peers and other adults, and engage in both classroom and other school-based activities (Feldman \& Matjasko, 2005). School engagement or a student's school experience is often measured across affective, behavioral, and cognitive domains (Jimerson, Campos, \& Greif, 2003). Both affective and behavioral components of a student's school experience are important to an examination of psychosocial outcomes (Johnson, Crosnoe, \& Elder, 2001). Consistent with Hirschi's (1969) delineation of school integrative processes, student's attachment (affective) and involvement or investment in schools (behavioral) are further explored here.

School bonding is a central element of the affective domain of school integration. Catalano, Haggerty, Oesterle, Fleming, and Hawkins (2004) contend that when an adolescent is bonded to school, their behavior becomes more consistent with the norms and values of the school. Conceptually, aspects of bonding to school, such as positive relationships with teachers and other school staff, may provide a supportive context within which adolescents can experience successful emotional, behavioral, and academic adjustments (Murray \& Greenberg, 2000), and develop positive coping and adaptive mechanisms (Resnick et al., 1997), which in turn may foster better psychosocial outcomes. However, more research is needed to confirm these positive associations. The available literature shows that school bonding, connectedness, or integration has been related to better well-being and lower disorder (Murray \& Greenberg, 2000) and fewer incidences of suicidal behavior (Maimon \& Kuhl, 2008). Specifically, Murray and Greenberg (2000) found that students who reported better relationships with teachers and more positive school experiences had greater social and emotional adjustment (e.g., general social competence) and reduced negative adjustment scores (e.g., depression, conduct problems).

Both academic grades and school-based extracurricular involvement (e.g., sports, clubs) represent important behavioral components of school integration, 
which are viewed as observable actions or performance. Activities such as completion of homework, grades, and scores on achievement tests (Jimerson et al., 2003) may be indicative of an adolescent's investment in school (Maddox \& Prinz, 2003), and subsequently their integration into the school environment (Maimon \& Kuhl, 2008). The relation between academic activities and mental health has been documented (e.g., Roeser, Eccles, \& Freedman-Doan, 1999). Although the associations are potentially reciprocal in nature, Hoge, Smit, and Hanson (1990) noted the positive influence of schoolwork and grades on aspects of well-being such as self-esteem.

In the context of adolescent development, involvement in structured, productive activities promotes prosocial behavior and a sense of group identification, and fosters and enhances new skills and interests, resulting in present and future academic and career successes and protection against risk-related actions (Eccles, Barber, Stone, \& Hunt, 2003). Furthermore, engagement in extracurricular activities may provide adolescents a constructive outlet for self-expression and identity development (Feldman \& Matjasko, 2005) and affords adolescents the opportunity to develop meaningful relationships with adults and peers in a positive setting outside of the classroom (Fredricks \& Eccles, 2005; Mahoney, Cairns, \& Farmer, 2003). Fredricks and Eccles (2005) reported that extracurricular participation was related to more favorable psychological adjustment among high school students. Specifically, the authors found that participation in activities such as student government, cheerleading, or the pep club promoted a greater sense of self-worth and lower depressive symptoms. School activity participation has also been positively associated with self-esteem (Perry-Burney \& Takyi, 2002) and increased interpersonal competence across adolescence (Mahoney et al., 2003), and inversely related to social isolation (Barber, Eccles, \& Stone, 2001). In summary, we contend that school behavioral activities are thought to influence adolescent psychosocial well-being through processes related to either a reduced sense of isolation or greater connectedness, or both.

This review of the literature reveals that both the behavioral and affective dimensions of school integration are related to mental health problems and well-being. These findings support Durkheim's theory that the more socially connected an individual feels, the less emotional distress he or she experiences, thus lowering the risk for adverse psychosocial outcomes.

\section{Religion}

The behavioral and affective dimensions of religion explored in this study have been adapted from research in health sociology and are consistent with a large body of work demonstrating that religious participation and subjective religiosity are inversely related to mental health issues such as rates of suicide, anxiety disorders, depression, and substance use (Koenig, McCullough, \& Larson, 2001). Religion has been positively associated with various measures of psychological well-being, positive psychosocial traits, and self-regarding attitudes (e.g., optimism, self-esteem; Koenig et al., 2001). As the research has focused primarily on adults, exploring the nature and extent of religious participation and salience among Black adolescents is an important step in furthering our understanding of the influence of religion on their mental health. This is particularly significant as studies have found that Black adolescents typically attend church often, place a high value on religion, and utilize religion as coping and social support resources during times of crisis (Donahue \& Benson, 1995).

Religion has been noted as an important socialization influence for adolescents supporting positive developmental outcomes and protecting against negative functioning and behavior (Ball, Armistead, \& Austin, 2003; Wallace \& Forman, 1998). Specifically, participation in religious organizations is postulated to promote a sense of shared values and beliefs, positive social connections, and an exchange of caring and support (Milot \& Ludden, 2009; Schnittker, 2001). In turn, this may foster coping mechanisms that help adolescents successfully handle typical as well as difficult life experiences. Some religion researchers conceptualize the institution as a social control mechanism (Regnerus, 2003), consequently deterring its participants from engaging in risky or deviant behavior. Within this conceptualization, individuals conform to the values and norms of acceptable behavior, and the moral standards of the religious group. Through regular participation, communication, and interaction among group members, these values and norms are reinforced, thereby reducing the risk of opportunity and proclivity to engage in problem behaviors, and protecting against negative psychological functioning (Milot \& Ludden, 2009).

Among adolescents, religious involvement has been positively related to psychosocial well-being outcomes such as general self-esteem (Ball et al., 2003) and life satisfaction (Mosher \& Handal, 1997). Ball et al. (2003) observed that the highest 
levels of self-esteem were found among those who attended church a few times a month. Interestingly, the same study also reported that the lowest levels of self-esteem were found in adolescents who attended nearly every day and who never attended. Milot and Ludden (2009), however, reported no significant associations between church attendance or religious youth group involvement and general self-esteem. Religious involvement has also been related to lower suicide ideation and attempts (Donahue \& Benson, 1995), psychological distress (Nonnemaker, McNeely, \& Blum, 2003), and depressive symptoms (Harker, 2001; Schapman \& Inderbitzen-Nolan, 2002). Harker (2001) found that adolescents are protected against high levels of depression when they attend church more often. In the same study, frequency of prayer, which is more of a salience or subjective dimension, was related to positive well-being outcomes, whereas church attendance was not. The author notes that the physical presence of supportive adults and others may be the key factor in reducing adverse outcomes. In contrast, more personal connections to religion may promote better well-being (Harker, 2001). This suggests that various aspects of religion may differentially influence adolescent well-being outcomes.

Taylor, Mattis, and Chatters (1999) explain subjective religiosity as attitudes or perceptions toward religion, usually measured by questions about being religious, religious importance, and beliefs in daily religious life. Using a measure of religious importance, Schnittker (2001) found that adolescents who reported moderate levels of importance are less depressed than those for whom religion is very important or not at all important in their daily lives. Welch, Petee, and Tittle (1991) suggest that for adolescents, commitment to religiosity (e.g., Bible study) must be conceptually differentiated from frequency of church attendance, as the latter is often due to parental influence. For instance, in addition to organized religion measures, Schapman and Inderbitzen-Nolan (2002) explored a newer concept in the mental health and religion literature by examining a dimension of religiosity that accounts for adolescent desire to participate in religious activities versus being forced to participate. They reported correlations between a greater desire to participate and lower depressive symptoms (e.g., lower interpersonal distress scores). The authors further noted that variation within this construct may influence the association between actual participation and mental health and highlighted the importance of addressing this possibility in future studies.
This research supports Durkheim's theoretical postulations that connection to a religious collective life is related to lower mental health problems and better psychosocial well-being outcomes. Schnittker (2001) emphasized that the two most salient products of religious integration are indicators of attendance at religious services and individual religious salience. As adolescents may indeed be attending due to parental force or influence, it is important to conceptually distinguish and operationally define actual attendance and participation from more subjective aspects of religiosity like importance of participation or desire to attend. Therefore, in this study, and consistent with Schapman and Inderbitzen-Nolan's (2002) propositions, both religious involvement (e.g., attendance) and commitment (e.g., self-directed choice to attend) will be examined as separate but related aspects of religious integration. In addition, we will examine the influence of commitment on the link between religious involvement and adolescent psychosocial well-being.

\section{The Current Study}

Family, school, and religion are three important social contexts in the lives of adolescents. From a Durkheimian perspective, positive involvement and attachments to these important socialization agents can facilitate a supportive and constructive atmosphere for adolescents, thereby contributing to optimal psychosocial well-being as well as serving as a protective influence against adverse psychosocial well-being. The review of the literature revealed that less information was available about how these social contexts fostered the well-being of adolescents in general and for Black adolescents in particular. Indeed, Black adolescents were minimally represented in much of the literature examining psychosocial well-being, indicating a key gap in the literature. This study is designed to address those gaps and to test the overarching hypotheses that family, school, and religious integration are significantly related to the mental health of Black adolescents. Specifically, we hypothesize that positive psychosocial well-being will be significantly predicted by higher family, school, and religious integration. Similarly, we expect that negative psychosocial well-being will be significantly predicted by lower family, school, and religious integration. We also expect that religious commitment will significantly mediate the association between religious involvement and the psychosocial well-being outcomes.

The study has a number of potential strengths. First, much of the previous literature utilized either 
large probability samples of adolescents overall or smaller, more homogeneous samples of subgroups of adolescents to examine mental health outcomes among adolescent populations. Subsequently, our understanding of the developmental experience of Black adolescents in relation to factors that foster optimal mental health outcomes has been limited. For this study, we use a large nationally representative sample of Black adolescents which helps to address the limited representation of Black adolescents in previous mental health research, subsequently increasing our knowledge about the mental health of this adolescent subgroup. Second, consistent with more recent definitions of mental health, we examine the construct using a broader conceptualization. For our research, mental health is represented by both the presence of positive psychosocial well-being indicators and the absence of or lower psychosocial dysfunction. Third, we utilize multiple measures of each aspect of social integration to explore the concomitant impact of family, school, and religion on the psychosocial well-being of Black adolescents. Previous studies have examined the discrete effects of family, school, and religion on the developmental context of adolescents in general; however, few studies explicate how these social contexts function together, within a system of interrelationships, to impact Black adolescent well-being outcomes. Fourth, we examine religious commitment and the potential role of this construct in mediating the link between religious involvement and the well-being outcomes. The direct effect of involvement has been established among adults, but is equivocal among adolescents. This study will test the direct and indirect effects of religious involvement among Black adolescents.

\section{Method}

\section{Study Design and Sample}

This research is a secondary analysis of the adolescent sample of the 2001-2003 National Survey of American Life (NSAL; Jackson et al., 2004), conducted by researchers at the Program for Research on Black Americans through the University of Michigan's Institute for Social Research. The NSAL is an IRB-approved nationally representative household survey, providing extensive data on mental disorders and the mental health of adult Americans of African ancestry. The NSAL utilized a stratified and clustered sample design to obtain a nationally representative sample of 3,570 African American (AA), 1,006 non-Hispanic Whites, and
1,621 Blacks of Caribbean descent (CBs) aged 18 years and older (see Jackson et al., 2004, for more detailed information about the NSAL). To generate the NSAL-A, every AA and CB household that included an adult participant in the NSAL was screened for an eligible adolescent living in the household, and adolescents were selected using a randomized procedure. If more than one adolescent in the household was eligible, up to two adolescents were selected for the study, and if possible, the second adolescent was of a different gender (Joe, Baser, Neighbors, Caldwell, \& Jackson, 2009). The NSAL-A weight was designed to adjust for variation in probabilities of selection within households, and nonresponse rates for adolescents and households. The weighted data were poststratified to approximate the national population distributions for gender (male and female subjects) and age (13-, 14-, 15-, 16-, and 17-year-old) subgroups among Black youth (Joe et al., 2009). The weighting process allows us to make accurate inferences about the national population of Black youth. The sample design and weight characteristics classify the NSAL-A as a complex sample survey.

Before the interview, informed consent and assent were obtained from the adolescent's legal guardian and adolescent, respectively. Trained interviewers used a computer-assisted instrument to conduct most of the interviews in the adolescents' homes. In addition, about $18 \%$ were conducted either in part or fully by telephone. Respondents were paid $\$ 50$ for their participation in the study; the overall response rate was $80.6 \%(80.4 \%$ for AAs and $83.5 \%$ for CBs). Only AA and CB adolescents were interviewed. The original adolescent sample consisted of 1,193 cases, but 23 were dropped from analyses because they were 18 or older at the time of the interview. Consequently, the resulting analysis sample consisted of 1,170 AA $(n=810)$ and CB $(n=360)$ youth ranging in age from 13 to 17 years (Joe et al., 2009).

\section{Measures}

\section{Mental Health (Positive Psychosocial Well-Being)}

This construct comprised three indicators: selfesteem, active coping, and mastery. Self-esteem was measured by the 10-item Rosenberg Self-Esteem Scale (Rosenberg, 1965), with items such as, "On the whole, I am satisfied with myself." A 4-point response set was used ranging from 1 (strongly agree) to 4 (strongly disagree). Positively worded items were reverse coded. Higher scores indicate 
better self-esteem $(\alpha=.72)$. The John Henryism Scale (James, 1996) is a 12-item measure of high effort coping, with items such as, "Hard work has really helped me to get ahead in life." Responses were measured on a 4-point scale ranging from 1 (completely true) to 4 (completely false). Each item was reverse coded. Higher scores represent higher levels of active coping $(\alpha=.71)$. The seven-item Pearlin's Mastery Scale (Pearlin \& Schooler, 1978) assesses individuals sense of control over their lives. A sample item from the scale is, "I can do just about anything I set my mind to." A 4-point response set was used ranging from 1 (strongly agree) to 4 (strongly disagree). Positive items were reverse coded. Higher mean scores indicate greater mastery $(\alpha=.68)$.

\section{Mental Health (Negative Psychosocial Well-Being)}

This construct included two indicators: perceived stress and a summary variable measuring lifetime diagnosis of adolescent mental disorder. The Cohen's Perceived Stress Scale (Cohen, Kamarck, \& Mermelstein, 1983) measures individual appraisal of situations in their life as stressful. A sample item from the scale is, "In the last month, how often have you felt nervous and stressed out?" The scale consists of 14 items, and rating items include responses ranging from 1 (never) to 5 (very often). Positively worded items were reverse scored. Higher scores suggest greater levels of perceived stress $(\alpha=.77)$. To measure mental disorders, adolescents completed a diagnostic interview using a modified version of the World Mental Health Composite International Diagnostic Interview (WMHCIDI) based on the World Health Organization Composite International Diagnostic Interview (WHO-CIDI) (Kessler \& Ustun, 2004). In this study, the lifetime diagnosis summary variable $(0=$ no disorder, $1=$ one or more disorders) was used to indicate whether respondents met the criteria for any anxiety, mood, impulse, substance abuse, or eating disorder.

\section{Family Integration}

This construct included three indicators: anticipated family support, family closeness, and family communication. The three-item Anticipated Support Scale uses a 4-point response set with items ranging from 1 (a great deal) to 4 (none). A sample item asks adolescents, "If you were sick, how much would the people in your family be willing to help out?" Items were all reverse scored so that higher mean values indicate greater anticipated support $(\alpha=.72)$.
Family closeness was measured by a question asking adolescents how close they feel to family members. Higher scores represent greater closeness to family. Frequency of communication with family or relatives not residing with the adolescent was measured by the question, "How often do you see, write, and talk on the telephone with, or e-mail family or relatives who do not live with you?" Higher responses indicate greater levels of communication with extended family. All family integration indicators were derived from the National Survey of Black Americans (NSBA; Jackson \& Neighbors, 1997).

\section{School Integration}

School bonding, school activity participation, and grades are included as representations of the affective and behavioral aspects of school integration. The nine-item School Bonding Scale measures adolescent affective connection and attitude toward school. A sample item from the scale is, "Most of my teachers treat/ed me fairly." Responses were measured on a 4-point scale ranging from 1 (very true) to 4 (not at all true). Positively worded items were reverse scored. Higher scores represent greater bonding to school $(\alpha=.71)$. The school-based extracurricular activity measure asked adolescents the number of years they participated in each of five categories of school-based extracurricular activities (sports teams other than gym; band, orchestra, or chorus; student newspaper or yearbook; student council or honor society; and any other school clubs, teams, or organizations). Each activity category was recoded and a new variable computed to form an activity score ranging from 0 (no activity participation) to 5 (participation in all activities). Grades were measured by asking the adolescent about the kind of grades they usually receive: mostly A's, mostly B's, mostly C's, mostly D's, or mostly failing grades. All school integration indicators were derived from the National Comorbidity Survey: Adolescent Supplement (NCS-A; Kessler, 2011).

\section{Religious Integration}

Religious attendance and participation comprised the first latent construct of religious integration. Indicators of involvement included church attendance, participation during church service, and church-related activities. Religious service attendance was measured by the question, "How often do you usually attend religious services?" Participant responses ranged from 1 (nearly every day-4 or more times a week) to 6 (never). Responses 
were reverse coded such that higher numbers represent greater church attendance. Religious service participation was measured by the question, "Do you do things like sing in the choir, read scripture, or other things like that during service?" The variable was recoded such that $0=$ no service participation and $1=$ service participation. Adolescent participation in activities at a religious institution, outside of church service, was measured by the question, "Besides regular services, how often do you take part in other activities at your place of worship?" Responses ranged from 1 (nearly every day-4 or more times a week) to 5 (never). The variable was recoded and higher numbers represent greater participation. Religious commitment represented the second religious integration latent construct. Indicators include choice to attend religious services and choice to participate in church-related activity. Both items asked if adolescents attended or participated in services or activities because they wanted to or because their parents or guardians made them go. Participants responded: 1 (choose), 2 (parents/guardians make you go), or 3 (both). Responses were recoded so that higher values represent adolescent self-directed choice to attend and lower numbers represent the parent making the adolescent attend. All religion questions were derived from the NSBA (Jackson \& Neighbors, 1997).

\section{Control Variables}

Age (treated as a continuous variable), gender, ethnicity (AA or CB; based on the adult in the household), and income (based on the adult report of family income) are included as relevant controls. Income was recoded into four categories: $1=\$ 0-17,999, \quad 2=\$ 18,000-31,999, \quad 3=\$ 32,000$ 54,999 , and $4=\$ 55,000$ and above.

\section{Analytic Strategy}

Chi-square tests of association were used to examine categories of demographic characteristics by ethnicity. Analyses were conducted using the complex sample module of SPSS Statistics 19 (IBM, Armonk, NY). Structural equation models (SEMs) were used to test the effects of the integration variables on the psychosocial well-being outcomes. A two-step procedure was employed for SEM model development (Kline, 2005). First, a six-latent-factor measurement model was specified to assess the adequacy of the observed indicators as measures of their respective latent factors. The second step involved assessment of the structural model fit and analysis of the structural relations, controlling for the sociodemographic variables. The structural model was specified with direct paths from control variables to latent factors and direct paths from the family, school, and religion factors to both mental health factors. A path from religious involvement to religious commitment was included to examine the indirect effect of religious involvement on the psychosocial well-being factors. Evaluation of all hypothesized effects was made using the most parsimonious final model with all nonsignificant paths from controls to latent factors and nonsignificant covariances set to zero. All missing data were coded -999 , the full sample of 1,170 was retained, and the raw data file was utilized for analysis. The models were estimated using Mplus Version 6.12 (Muthén \& Muthén, 1998-2010), which accounts for the complex sample survey design and uses a robust weighted least squares approach (WLSMV) to estimate latent variables with both continuous and categorical indicators. With this estimator, the data missing methodology is pairwise present and the categorical data methodology handles any floor or ceiling effects for categorical outcomes (Muthén \& Muthén, 1998-2010). Estimates of the indirect effects and corresponding delta method standard errors were computed in Mplus; these were examined to confirm mediation (MacKinnon, Lockwood, Hoffman, West, \& Sheets, 2002).

Model fit was evaluated by examining the chisquare statistic, comparative fit index (CFI), and root mean square error of approximation (RMSEA). The $\chi^{2}$ statistic is sensitive to larger sample sizes and may be significant even with a small discrepancy between the observed and model-implied covariances (Kline, 2005), thus the normed chi-square (NC; i.e., $\chi^{2} / d f$ ) will also be included. Acceptable model fit criteria included a nonsignificant model $\chi^{2}$ value, NC ratio $<2$, CFI above .90, and RMSEA $\leq .08$ (Kline, 2005; Tabachnick \& Fidell, 2007).

\section{Results \\ Descriptive Findings}

Table 1 displays the findings of the chi-square analyses examining the sample's demographic characteristics. Statistical significance for this analysis is based on the design-adjusted $F$ and its degrees of freedom. Results revealed that there was a significant difference in age between $\mathrm{AA}$ and $\mathrm{CB}$ adolescents. There is a larger number of 13-year-old AA $(20.8 \%)$ compared to CB $(10.6 \%)$ adolescents. Conversely, more CB adolescents $(28.3 \%)$ are in the 15 -year-old age group than AA adolescents (20.0\%). 
Table 1

Unweighted and Weighted Distributions of Demographic Characteristics of the National Survey of American Life Adolescent Sample by Ethnicity

\begin{tabular}{|c|c|c|c|c|c|c|c|}
\hline & \multicolumn{3}{|c|}{$\begin{array}{l}\text { African American } \\
\qquad n^{\mathrm{a}}=810\end{array}$} & \multicolumn{3}{|c|}{$\begin{array}{c}\text { Caribbean Black } \\
\qquad n^{\mathrm{a}}=360\end{array}$} & \multirow{2}{*}{$\begin{array}{l}\text { Characteristic } x \\
\text { Ethnicity } \\
\chi^{2}\end{array}$} \\
\hline & $\mathrm{n}^{\mathrm{a}}$ & $\% u w t^{b}$ & $\% w t^{c}$ & $\mathrm{n}^{\mathrm{a}}$ & $\% u w t^{b}$ & $\% w t^{c}$ & \\
\hline \multicolumn{8}{|l|}{ Gender } \\
\hline Male & 398 & 49.1 & $50.4(1.9)$ & 165 & 45.8 & $44.8(2.3)$ & \multirow[t]{2}{*}{$\chi^{2}=3.48, p=.07$} \\
\hline Female & 412 & 50.9 & $49.6(1.9)$ & 195 & 54.2 & $55.2(2.3)$ & \\
\hline \multicolumn{8}{|l|}{ Age of respondent } \\
\hline 13 & 165 & 20.4 & $20.8(1.9)$ & 56 & 15.6 & $10.6(1.2)$ & \multirow[t]{5}{*}{$\chi^{2}=3.50, p=.04$} \\
\hline 14 & 184 & 22.7 & $20.1(1.6)$ & 72 & 20.0 & $20.2(1.4)$ & \\
\hline 15 & 135 & 16.7 & $20.0(1.6)$ & 79 & 21.9 & $28.3(4.3)$ & \\
\hline 16 & 153 & 18.9 & $20.2(1.8)$ & 74 & 20.6 & $18.4(4.4)$ & \\
\hline 17 & 173 & 21.4 & $18.9(1.2)$ & 79 & 21.9 & $22.5(1.1)$ & \\
\hline \multicolumn{8}{|l|}{ Household income $^{\mathrm{d}}$} \\
\hline$\$ 0-\$ 17,999$ & 244 & 30.2 & $27.7(2.5)$ & 67 & 18.8 & $26.2(5.2)$ & \multirow[t]{4}{*}{$\chi^{2}=0.97, p=.36$} \\
\hline$\$ 18,000-\$ 31,999$ & 223 & 27.6 & $27.4(1.8)$ & 107 & 30.0 & $20.3(3.2)$ & \\
\hline$\$ 32,000-\$ 54,999$ & 187 & 23.2 & $24.6(2.4)$ & 94 & 26.3 & $33.2(4.2)$ & \\
\hline$\geq \$ 55,000$ & 153 & 19.0 & $20.2(2.2)$ & 89 & 24.9 & $20.3(6.7)$ & \\
\hline
\end{tabular}

Note. All weighted estimates are weighted to be nationally representative of the given population and subpopulations in the contiguous 48 states of the United States. Standard errors and $\chi^{2}$ statistics are adjusted for the sampling stratification, clustering, and weighting of the data.

${ }^{\text {a}}$ Sample size $(n)$ is unweighted. ${ }^{b}$ Unweighted. ${ }^{c}$ Weighted (standard error). ${ }^{d}$ Reflects adult respondents' status.

Although not statistically significant, there are a slightly greater percentage of CB female adolescents than any other male or female group.

\section{Measurement Model}

Preliminary data analysis supported the six-factor model as proposed in the hypothesis as the best model for further analysis. The six-factor model (Figure 1) had an acceptable fit to the data, $\chi^{2}(d f=89)=143.058, \quad p<.001, \quad \mathrm{NC}=1.61, \mathrm{CFI}=$ .942 , RMSEA $=.023,90 \%$ CI $[0.016,0.030]$. All standardized factor loadings were .31 or greater and statistically significant $(p<.001)$, suggesting that the latent factors significantly predicted their observed outcomes. Factor loadings of .30 or above have been suggested to adequately define a factor (Brown, 2006).

\section{Structural Model}

The final structural model reflecting partial mediation was specified with direct paths from control variables to all latent factors; direct paths from family integration, school integration, religious involvement, and religious commitment to both psychosocial well-being variables; and an indirect route from religious involvement to religious commitment to the well-being variables. The model is displayed in Fig- ure 2, with standardized path coefficients. Paths from control variables to latent factors are not displayed. The model had an acceptable fit to the data, $\chi^{2}(d f=147)=230.402, \quad p<.001, \quad \mathrm{NC}=1.57$, CFI $=.910$, RMSEA $=.022,90 \%$ CI [0.016, 0.027]. All direct and indirect effects are discussed based on the standardized path coefficients.

\section{Direct Effects of Integration on Psychosocial Well-Being Outcomes}

Family integration, school integration, and religious commitment were significantly associated with positive psychosocial well-being and negative psychosocial well-being in the hypothesized directions. School integration was the strongest predictor of both psychosocial well-being outcomes. Unexpectedly, a significant but inverse direct path was observed between religious involvement and positive psychosocial well-being, suggesting that the lower the religious involvement, the greater the positive psychosocial well-being. Similarly, a significant positive path was found between lower religious involvement and lower psychosocial wellbeing. Forty-five percent of the variance in positive psychosocial well-being and $35 \%$ of the variance in negative psychosocial well-being was due to family, school, and religion, and any significant controls. 


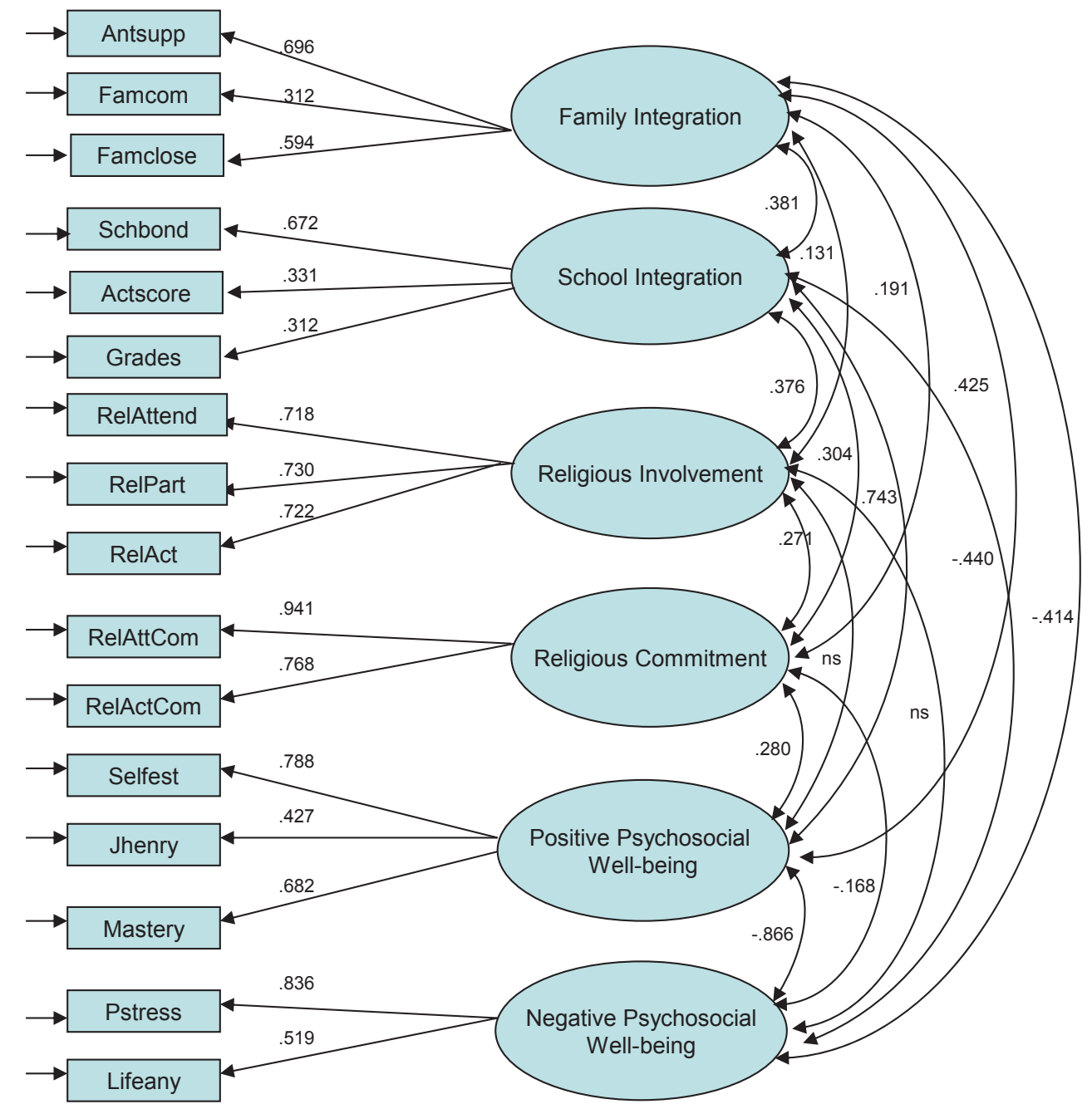

Figure 1. Final confirmatory factor analysis model. Completely standardized parameter estimates are shown. All paths were significant at $p<.05$, unless designated ns. Values for error covariances are not shown. Antsupp = anticipated family support; Famcom $=$ family communication; Famclose = family closeness; Schbond = school bonding; Actscore = activity score; Grades = grades; Relattend = religious service attendance; Relpart = religious service participation; Relact $=$ attendance are religious activities outside of services; Relattcom $=$ commitment to religious service attendance; Relactcom $=$ commitment to attendance at religious activities outside of services; Selfest $=$ self-esteem; Jnenry $=$ John Henryism; Mastery = mastery; Pstress = perceived stress; Iifeany = lifetime diagnosis of mental disorders.

Indirect Effects of Religious Involvement on Psychosocial Well-Being Outcomes

Religious commitment was hypothesized to mediate the effect of religious involvement on both psychosocial well-being outcomes. A statistical test of the indirect effect formally tests the mediating effect of religious commitment. Partial mediation is said to occur when both the direct and indirect effects are significant. Results revealed a significant positive path between religious involvement and religious commitment (Figure 2). As previously noted, religious involvement and religious commitment were significantly associated with both psychosocial well-being variables. Therefore, there was a significant indirect effect such that religious commitment partially mediated the effect of religious involvement on positive psychosocial well-being $(.091, S E=.033, p<.05)$ and lower psychosocial well-being $(-.061, S E=.022, p<.05)$.

\section{Discussion}

Although the influence of family, school, and religious social contexts on the mental health of adolescents has been documented, limited literature has focused on the significance of these contexts for 


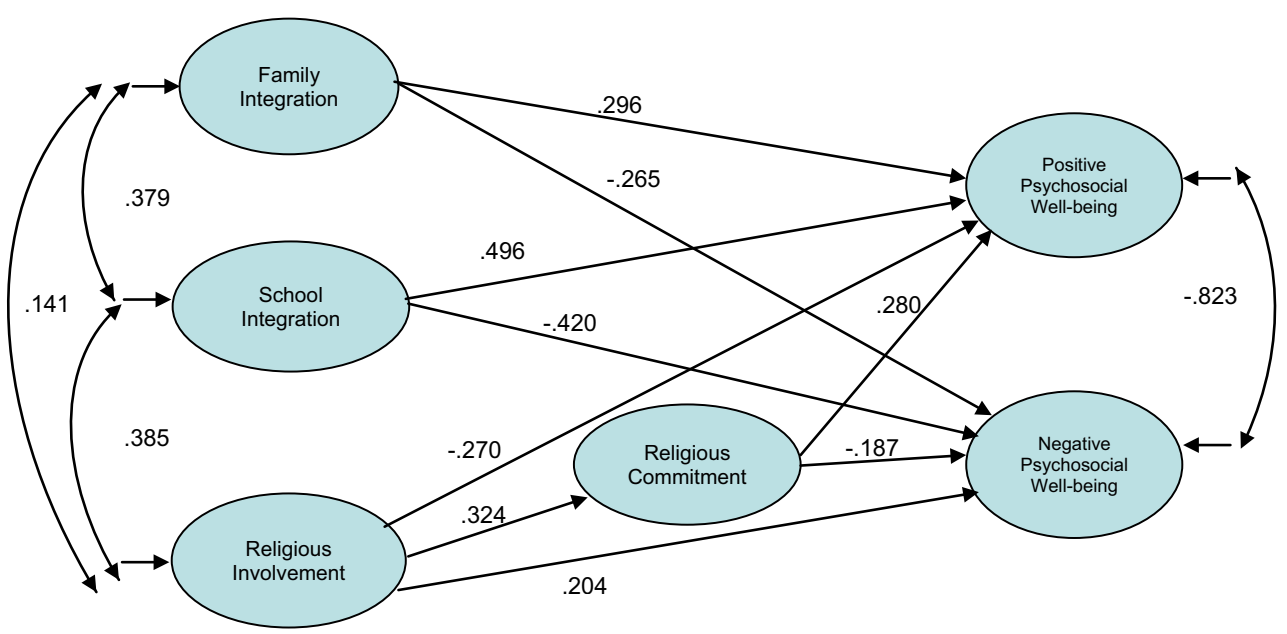

Figure 2. Final structural model with partial mediation, controlling for significant sociodemographic variables (not shown). Completely standardized parameter estimates are shown. All paths and indirect effects were significant at $p<.05$. Indirect effect from religious involvement to positive psychosocial well-being $(.091, S E=.033, p<.05)$. Indirect effect from religious involvement to negative psychosocial well-being $(-.061, S E=.022, p<.05)$.

enhancing better mental health outcomes among Black adolescents. Thus, this study contributes to the advancement of knowledge in a number of ways. First, the study utilized a national probability sample of Black adolescents. This design provides a critical addition to the limited research on factors that promote the mental health of this subgroup of adolescents, previously underrepresented in mental health research. Second, the study used a conceptualization of mental health that incorporates both the presence of positive psychosocial well-being and the absence of or lower psychosocial dysfunction. Mental health, viewed in this way, is consistent with more recent definitions that emphasize the inclusion of positive aspects of well-being and underscore the importance of indicators that represent well-being and dysfunction across biopsychosocial spheres (e.g., Kazdin, 1993). Third, the study utilized a statistical analysis procedure that allowed for the simultaneous assessment of family, school, and religion factors in relation to mental health outcomes. Understanding how these factors function within a system of interrelationships provides an important picture of the processes most salient to psychosocial development during the adolescent years. Fourth, the study provided information on a newer concept in the adolescent religion literature that highlights the importance of the religious commitment of adolescents as a means to understand the overall influence of religious integration among this group. Finally, although the study was not a direct test of Durkheim's social integration theory, it does provide support for the use of the theory to explore the relative importance of these three important social contexts for adolescent well-being. The theory has been traditionally used to explore factors that protect against negative outcomes (e.g., Maimon \& Kuhl, 2008). However, we utilized Durkheim's theory to investigate how integration into key developmental social contexts fosters better psychosocial well-being among Black adolescents.

Overall, study findings support the hypotheses that family, school, and religious integration are significant predictors of better mental health for Black adolescents, with school integration emerging as the strongest predictor of both well-being outcomes. The results also support the hypothesis that religious commitment significantly mediates the association between religious involvement and the psychosocial well-being outcomes.

The findings illustrate that Black adolescents who are more integrated into their family, through closer relationships, expectations of support, and greater communication with their kinship network, experience better psychosocial well-being and less psychosocial dysfunction. Maimon and Kuhl (2008) suggest that stronger affective connections to family lead to a level of emotional stability that maintains its importance beyond the influence of other key adolescent social contexts. Our results are consistent with previous empirical research (e.g., Margolin, 2006) and substantiate the positive influence of greater family closeness, support, and communication on better mental health outcomes among Black adolescents even when considering school and religious factors. The results also make the case that 
communication with family members, even among kinship networks, might serve to establish, through encouragement and positive reinforcement, a developmental context beneficial to healthy self-esteem and a strong sense of mastery, which are critical for the adolescent as they progress through developmental stages (Erickson, 1968). These findings highlight the importance of continuing to foster closeness and communication between adolescents and their immediate and extended family members in an effort to promote better adolescent psychosocial development.

Current findings support and add to the burgeoning literature on school engagement in that greater integration into school was related to fewer problem outcomes and better psychosocial wellbeing outcomes. Previous research supports the positive influence of school bonding, grades, and participation on school activities on self-esteem, and social and emotional adjustment (e.g., Murray \& Greenberg, 2000). Greater school integration also was related to fewer incidences of poorer well-being (e.g., depression, conduct problems) in the extant literature (e.g., Fredricks \& Eccles, 2005). This study adds to the growing body of research on school integration and positive psychosocial well-being outcomes, particularly for Back adolescents. School can be viewed as a key influence in the lives of adolescents secondary to family (Simons-Morton et al., 1999). For adolescents in this study, school integration was reflected by bonding to school (including teachers), involvement in school activities, and school grades. The school environment and relationships formed thereof provide another supportive context within which adolescents can interact with nonfamilial adults, such as teachers or other school staff (e.g., social workers) who may subsequently serve as informal mentors, providing guidance and direction on a variety of issues related to adolescent life. Participation in school activities generates a shared experience with peers and a sense of camaraderie among the adolescent activity group. Activity participation and doing well in school may also contribute to a sense of accomplishment, development of skill, and feeling of mastery over particular aspects of school, which may foster greater selfesteem and less emotional stress. Conversely, adolescents who are less connected to school may be at higher risk for poor psychosocial well-being. The study findings emphasize the importance of assessing school connections and involvement when considering factors that influence adolescent development and specifically support better psychosocial well-being among Black adolescents.
Religious involvement, a behavioral representation of religious integration, provides an opportunity for adolescents to interact and form relationships with positive peers and adults in a supportive environment where there are shared values and beliefs (Milot \& Ludden, 2009). It is also an activity typically engaged with family and extended family. These exchanges are a source of well-being, fostering mechanisms that help the adolescent cope with normal as well as challenging situations (Ball et al., 2003; Regnerus, 2003). We sought to understand the influence of religious involvement and commitment on the mental health of Black adolescents, and if religious involvement affected mental health through more of a commitment to religion.

Our findings that higher religious commitment (i.e., adolescent self-directed choice to attend religious services and activities) was associated with greater levels of positive psychosocial well-being and less psychosocial dysfunction are novel. To our knowledge, the only other study to examine the link between religious commitment, conceptualized in this way, and adolescent mental health was the work of Schapman and Inderbitzen-Nolan (2002), who reported that both greater religious activity participation and stronger desire to participate in these religious activities was related to less depressive symptoms (e.g., interpersonal distress) in a small sample of mostly White adolescents. Our results add to the limited literature on subjective religiosity and adolescent mental health, specifically underscoring the importance of adolescent choice or commitment to attend religious services in relation to the mental health of Black adolescents. For these adolescents, religious life may become more important as there are increased opportunities to interact with prosocial peers in an environment where there are consistent values and beliefs (Schnittker, 2001) and reflect their growing sense of independence. This may be at the root of their commitment to attending religious services and their supportive network may be the source of better well-being.

The analysis of the direct effect of religious involvement on both measures of mental health, such that greater involvement was related to lower incidences of positive psychosocial well-being and greater chance of experiencing psychosocial distress, revealed unexpected inverse associations. Although the literature on the impact of religious involvement in the lives of adolescents was somewhat tenebrous, our results were surprising given the importance of religion to Black adolescents (Donahue \& Benson, 1995). Ball et al. (2003) did 
suggest an inverse association between religious involvement and self-esteem, reporting that the lowest levels of self-esteem were evident for Black female adolescents who attended religious activities in high frequency (e.g., nearly every day). A possible explanation of the unexpected direction for the direct effect of religious involvement may rest with the idea that adolescents are primarily attending religious service activities due to parental influence. As such, it is likely that their physical presence in church is experienced as conforming to group (e.g., family) expectations, which by itself could potentially be a source of distress, given their increase need for autonomy. Although religious attendance might be high due to parental influences, adolescents' sense of obligation to participate in religious activities would not necessarily encourage a sense of well-being or determination over making personal choices; rather, it may increase their risk for poor psychosocial well-being. We contend that when an adolescent's religious attendance is high because it is their choice rather than their parent's influence, we would expect involvement effects to be mediated and in the right direction.

The results of the mediation analysis provided an examination of the noted assumptions. As hypothesized, a significant indirect effect was observed in that the relation between religious attendance and the mental health of Black adolescents was partially mediated by their sense of religious commitment. Specifically, when religious involvement was examined through religious commitment, adolescents who were higher attendees were also more committed, namely, attended church not because of parental influence, but rather their own choice, and this fostered better psychosocial well-being outcomes and reduced psychosocial distress. These findings suggest that for adolescents who are more consistent in their attendance, their commitment to attendance or their affective connections to being in that environment, whether with positive peers or among supportive adults, evinces a greater psychosocial benefit of religious involvement. This idea of commitment or choice to attend, then, is vital to our understanding of the role of religious involvement in the psychosocial development of Black adolescents.

\section{Limitations and Directions for Future Research}

Although this study evinced promising results, a number of key limitations must be recognized. First, the study utilized a cross-sectional survey design; consequently, no causal inferences can be made. It is possible that adolescents who have a strong sense of self-worth and feel greater control over their lives may also tend to report a closer relationship with teachers at school or feel confident enough to participate in school activities. This limitation is compounded by the use of retrospective and self-report data. Second, although the findings are generalizable to other adolescents of similar backgrounds, they are not generalizable to a broader non-Black adolescent population. Third, other important adolescent contexts, like peers, were not examined. Although it was the intent of this study to examine integration into social institutions, considering the peer context could contribute to a fuller understanding of how social contexts influence mental health outcomes. The literature on schools and religion both exemplify the opportunities adolescents have to develop relationships with peers through participation in school activities (Eccles et al., 2003) and religious activities (Milot \& Ludden, 2009). It is possible that adolescents are more integrated into these environments due to peer relationships that may be encouraging of behavior and consequent actions.

Future research could consider a longitudinal study design. This type of study could be useful for examining how significant associations among the variables change over time as the adolescent ages. In addition, studying other ethnic groups of adolescents may help determine if these findings are consistent across other adolescent subgroups or adolescents in general. The focus and scope of this study was to examine relations between study constructs for the overall sample of Black adolescents. Our next steps will be to examine within-group differences (e.g., Joe et al., 2009) as there is the potential for subpopulation variation in the measurement of constructs and in the association between constructs. For example, although Black adolescents may attend church regularly, older Black adolescents may exercise a greater level of freedom and autonomy through normal developmental activities like jobs, other recreational activities, access to a car, and peer-encouraged activities (Smith, Denton, Faris, \& Regnerus, 2002), which may reduce their attendance at religious activities. This would be important to consider as observed associations may apply to younger or middle adolescents mainly.

Overall, the study findings emphasize the importance of identifying family, school, and religion factors significant to better mental health outcomes that can, in turn, inform the design and further development of evidence-based promotion, 
prevention, and treatment interventions as well as culturally consonant interventions that enhance adolescent psychosocial well-being, particularly in Black adolescent populations. The findings of this study are useful for direct service practitioners, program developers, and policymakers who seek to reduce the burden of mental health problems among adolescents, through efforts to foster and build their mental health.

\section{References}

Ackard, D. M., Neumark-Sztainer, D., Story, M., \& Perry, C. (2006). Parent-child connectedness and behavioral and emotional health among adolescents. American Journal of Preventive Medicine, 30, 59-66. doi:10.1016/j. amepre.2005.09.013

Ball, J., Armistead, L., \& Austin, B. J. (2003). The relationship between religiosity and adjustment among African-American, female, urban adolescents. Journal of Adolescence, 26, 431-446. doi:10.1016/S0140-1971(03) 00037-X

Barber, B. L., Eccles, J. S., \& Stone, M. R. (2001). Whatever happened to the jock, the brain, and the princess? Young adult pathways linked to adolescent activity involvement and social identity. Journal of Adolescent Research, 16, 429-455. doi:10.1177/0743558401165002

Bean, R. A., Bush, K. R., McKenry, P. C., \& Wilson, S. M. (2003). The impact of parental support, behavioral control, and psychological control on the academic achievement and self-esteem of African American and European American adolescents. Journal of Adolescent Research, 18, 523-541. doi:10.1177/0743558403255070

Brown, T. A. (2006). Confirmatory factor analysis for applied research. New York, NY: Guilford Press.

Catalano, R. F., Haggerty, K. P., Oesterle, S., Fleming, C. B., \& Hawkins, J. D. (2004). The importance of bonding to school for healthy development: Findings from the social development research group. Journal of School Health, 74, 252-261. doi:10.1111/j.1746-1561.2004.tb08281.x

Chen, K. W., Killeya-Jones, L. A., \& Vega, W. (2005). Prevalence and co-occurrence of psychiatric symptom clusters in the U.S. adolescent population using DISC predicative scales. Clinical Practice and Epidemiology in Mental Health, 1, 1-12. doi:10.1186/1745-0179-1-22

Cohen, S., Kamarck, T., \& Mermelstein, R. (1983). A global measure of perceived stress. Journal of Health and Social Behavior, 24, 385-396. doi:10.2307/2136404

Crockett, L. J., \& Petersen, A. C. (1993). Adolescent development: Health risks and opportunities for health promotion. In S. G. Millstein, A. C. Petersen, \& E. O. Nightingale (Eds.), Promoting the health of adolescents: New directions for the twenty-first century (pp. 13-37). New York, NY: Oxford University Press.

Demo, D. H., \& Acock, A. C. (1996). Family structure, family process, and adolescent well-being. Journal of Research on Adolescence, 6, 457-488.
Donahue, M. J., \& Benson, P. L. (1995). Religion and the well-being of adolescents. Journal of Social Issues, 51, 145-160. doi:10.1111/j.1540-4560.1995.tb01328.x

Durkheim, E. (1951). Suicide: A study in sociology. New York, NY: Free Press.

Eccles, J. S., Barber, B. L., Stone, M., \& Hunt, J. (2003). Extracurricular activities and adolescent development. Journal of Social Issues, 59, 865-889. doi:10.1046/j. 0022-4537.2003.00095.x

Erickson, E. (1968). Identity: Youth and crisis. New York, NY: Norton.

Feldman, A. F., \& Matjasko, J. L. (2005). The role of school-based extracurricular activities in adolescent development: A comprehensive review and future directions. Review of Educational Research, 75, 159-210. doi:10.3102/00346543075002159

Fredricks, J. A., \& Eccles, J. S. (2005). Developmental benefits of extracurricular involvement: Do peer characteristics mediate the link between activities and youth outcomes? Journal of Youth and Adolescence, 34, 507-520. doi:10.1007/s10964-005-8933-5

Grusec, J. (2011). Socialization processes in family: Social and emotional development. Annual Review of Psychology, 62,243-269. doi:10.1146/annurev.psych.121208.131650

Harker, K. (2001). Immigrant generation, assimilation, and adolescent psychological well-being. Social Forces, 79, 969-1004. doi:10.1353/sof. 2001.0010

Hirschi, T. (1969). Causes of delinquency. Berkely: University of California Press.

Hoge, D. R., Smit, E. K., \& Hanson, S. L. (1990). School experiences predicting changes in self-esteem of sixth- and seventh-grade students. Journal of Educational Psychology, 82, 117-127. doi:10.1037/0022-0663.82. 1.117

Jackson, J. S., \& Neighbors, H. W. (1997). National survey of black Americans, waves 1-4, 1979-1980, 1987-1988, 1988-1989, 1992. ICPSR06668-v1. Ann Arbor, MI: InterUniversity Consortium for Political and Social Research. doi:10.3886/ICPSR06668.v1

Jackson, J. S., Torres, M., Caldwell, C. H., Neighbors, H. W., Nesse, R. M., Taylor, R. J., ... Williams, D. R. (2004). The National Survey of American Life: A study of racial, ethnic and cultural influences on mental disorders and mental health. International Journal of Methods in Psychiatric Research, 13, 196-207. doi:10.1002/ mpr.177

James, S. A. (1996). The John Henryism Scale for Active Coping. In R. J. Jones (Ed.), Handbook of tests and measurements for Black populations (pp. 417-425). Hampton, VA: Cobb \& Henry.

Jimerson, S. R., Campos, E., \& Greif, J. L. (2003). Toward an understanding of definitions and measures of school engagement and related terms. California School Psychologist, 8, 7-27.

Joe, S., Baser, R. S., Neighbors, H. W., Caldwell, C. H., \& Jackson, J. S. (2009). 12-month and lifetime prevalence of suicide attempts among Black adolescents in the National Survey of American Life. Journal of the Ameri- 
can Academy of Child \& Adolescent Psychiatry, 48, 271283. doi:10.1097/CHI.0b013e318195bccf

Johnson, M. K., Crosnoe, R., \& Elder, G. H. Jr (2001). Students' attachment and academic engagement: The role of race and ethnicity. Sociology of Education, 74, 318-340. doi: $10.2307 / 2673138$

Kazdin, A. E. (1993). Adolescent mental health: Prevention and treatment programs. American Psychologist, 48, 127-141. doi:10.1037/0003-066X.48.2.127

Kessler, R. C. (2011). National Comorbidity Survey: Adolescent Supplement (NCS-A), 2001-2004 (ICPSR28581-v4). Ann Arbor, MI: Inter-university Consortium for Political and Social Research. doi:10.3886/ICPSR28581.v4

Kessler, R. C., Avenevoli, S., Costello, J., Georgiades, K., Green, J. G., Gruber, M. J., ... Merikangas, K. M. (2012). Prevalence, persistence, and sociodemographic correlates of DSM-IV disorders in the national comorbidity survey replication adolescent supplement [Appendix tables]. Archives of General Psychiatry, 69, 372-380. http://www.hcp.med.harvard.edu/ncs/publi cations.php

Kessler, R. C., \& Ustun, T. B. (2004). The World Mental Health (WMH) Survey Initiative version of the World Health Organization (WHO) Composite International Diagnostic Interview (CIDI). International Journal of Methods in Psychiatric Research, 13, 93-121. doi:10.1002/ mpr.168

Keyes, C. L. (2006). Mental health in adolescence: Is America's youth flourishing? American Journal of Orthopsychiatry, 76, 395-402. doi:10.1037/0002-9432.76. 3.395

Kline, R. B. (2005). Principles and practice of structural equation modeling (2nd ed.). New York, NY: Guilford Press.

Knopf, D., Park, M. J., \& Mulye, T. P. (2008). The mental health of adolescents: A national profile, 2008. San Francisco, CA: National Adolescent Health Information Center. Retrieved from http://nahic.ucsf.edu/downloads/MentalHealthBrief.pdf

Koenig, H. G., McCullough, M., \& Larson, D. (2001). The handbook of religion and health. New York, NY: Oxford University Press.

Loh, E., \& Wragg, J. (2004). Developmental perspective. In K. N. Dwivedi \& P. B. Harper (Eds.), Promoting the emotional well-being of children and adolescents and preventing their mental ill-health: A handbook (pp. 29-48). London, UK: Kingsley.

MacKinnon, D. P., Lockwood, C. M., Hoffman, J. M., West, S. G., \& Sheets, V. (2002). A comparison of methods to test mediation and other intervening variable effects. Psychological Methods, 7, 83-104. doi:10.1037/ 1082-989X.7.1.83

Maddox, S. J., \& Prinz, R. J. (2003). School bonding in children and adolescents: Conceptualization, assessment, and associated variables. Clinical Child and Family Review, 6, 31-49. doi:10.1023/ A:1022214022478

Mahoney, J. L., Cairns, B. D., \& Farmer, T. W. (2003). Promoting interpersonal competence and educational success through extracurricular activity participation.
Journal of Educational Psychology, 95, 409-418. doi: 10.1037/0022-0663.95.2.409

Maimon, D., \& Kuhl, D. C. (2008). Social control and youth suicidality: Situating Durkheim's ideas in a multilevel framework. American Sociological Review, 73, 921-943. doi:10.1177/000312240807300603

Margolin, S. (2006). African American youths with internalizing difficulties: Relation to social support and activity involvement. Children and Schools, 28, 135-144. doi:10.1093/cs/28.3.135

Milot, A. S., \& Ludden, A. B. (2009). The effects of religion and gender on well-being, substance use, and academic engagement among rural adolescents. Youth $\mathcal{E}$ Society, 40, 403-425. doi:10.1177/0044118X08316668

Mosher, J. P., \& Handal, P. J. (1997). The relationship between religion and psychological distress in adolescents. Journal of Psychology and Theology, 25, 449-457.

Murray, C., \& Greenberg, M. T. (2000). Children's relationship with teachers and bonds with school an investigation of patterns and correlates in middle childhood. Journal of School Psychology, 38, 423-445. doi:10.1016/ S0022-4405(00)00034-0

Muthén, L. K., \& Muthén, B. O. (1998-2010). Mplus users guide (6th ed.). Los Angeles, CA: Muthén \& Muthén.

Nonnemaker, J. M., McNeely, C. A., \& Blum, R. W. (2003). Public and private domains of religiosity and adolescent health risk behaviors: Evidence from the National Longitudinal Study of Adolescent Health. Social Science E Medicine, 57, 2049-2054. doi:10.1016/ S0277-9536(03)00096-0

Pearlin, L. I., \& Schooler, C. (1978). The structure of coping. Journal of Health and Social Behavior, 19, 2-21. doi:10.2307/2136319

Perry-Burney, G. D., \& Takyi, B. K. (2002). Self-esteem, academic achievement, and moral development among adolescent girls. Journal of Human Behavior in the Social Environment, 5, 15-27. doi:10.1300/J137v05n02_02

Regnerus, M. D. (2003). Religion and positive adolescent outcomes: A review of research and theory. Review of Religious Research, 44, 394-413. doi:10.2307/3512217

Resnick, M. D., Bearman, P. S., Blum, R. W., Bauman, K. E., Harris, K. M., Jones, J., ... Shew, M. (1997). Protecting adolescents from harm: Findings from the National Longitudinal Study on Adolescent Health. JAMA, 278, 823-832. doi:10.1001/jama.1997.03550100049038

Roeser, R. W., Eccles, J. S., \& Freedman-Doan, C. (1999). Academic functioning and mental health in adolescence: Patterns, progressions, and routes from childhood. Journal of Adolescent Research, 14, 135-174. doi: $10.1177 / 0743558499142002$

Rosenberg, M. (1965). Society and the adolescent self-image. Princeton, NJ: Princeton University Press.

Rowling, L. (2006). Adolescence and emerging adulthood (12-17 years and 18-24 years). In M. Cattan \& S. Tilford (Eds.), Mental health promotion: A lifespan approach (pp. 100-136). Berkshire, UK: Open University Press.

Schapman, A. M., \& Inderbitzen-Nolan, H. M. (2002). The role of religious behaviour in adolescent depressive and 
anxious symptomatology. Journal of Adolescence, 25, 631-643. doi:10.1006/jado. 2002.0510

Schnittker, J. (2001). When is faith enough? The effects of religious involvement on depression. Journal for the Scientific Study of Religion, 40, 393-411. doi:10.1111/ 0021-8294.00065

Simons-Morton, B. G., Crump, A. D., Haynie, D. L., \& Saylor, K. E. (1999). Student-school bonding and adolescent problem behavior. Health Education Research, 14, 99-107. doi:10.1093/her/14.1.99

Smith, C., Denton, M. L., Faris, R., \& Regnerus, M. (2002). Mapping American adolescent religious participation. Journal for the Scientific Study of Religion, 41, 597-612. doi:10.1111/1468-5906.00148

Smith, M. (1959). Research strategies toward a conception of positive mental health. American Psychologist, 14, 673-681. doi:10.1037/h0040030

Stark, R., \& Bainbridge, W. S. (1996). Religion, deviance, and social control. New York, NY: Routledge.

Tabachnick, B. G., \& Fidell, L. S. (2007). Using multivariate statistics (5th ed.). New York, NY: Allyn \& Bacon.

Taylor, R. J., Chatters, L. M., \& Celious, A. K. (2003). Extended family households among Black Americans. African American Research Perspectives, 9, 133-151.

Taylor, R. J., Mattis, J., \& Chatters, L. M. (1999). Subjective religiosity among African Americans: A synthesis of findings from five national samples. Journal of Black Psychology, 25, 524-543. doi:10.1177/0095798499025004004

Thorlindsson, T., \& Bjarnason, T. (1998). Modeling Durkheim on the micro level: A study of youth suicidality. American Sociological Review, 63, 94-110. doi:10.2307/ 2657479

U.S. Department of Health and Human Services. (2001). Mental health: Culture, race, and ethnicity-A supplement to mental health: A report of the surgeon general. Rockville, MD: Author.

Wallace, J. M., Jr, \& Forman, T. A. (1998). Religion's role in promoting health and reducing risk among American youth. Health Education \& Behavior, 25, 721-741. doi: $10.1177 / 109019819802500604$

Welch, M. R., Petee, T., \& Tittle, C. R. (1991). Religion and deviance among adult Catholics: A test of the "Moral Communities" hypothesis. Journal for the Scientific Study of Religion, 30, 159-172. doi:10.2307/1387210

Wenk, D. A., Hardesty, C. L., Morgan, C. S., \& Blair, S. L. (1994). The influence of parental involvement on the well-being of sons and daughters. Journal of Marriage and the Family, 56, 229-234.

World Health Organization. (2010). Mental health: Strengthening our response (Fact Sheet No. 220). Retrieved from http://www.who.int/mediacentre/factsheets/fs220/en/ 